\title{
Nitrogen Sparing Induced by a Mixture of Essential Amino Acids Given Chiefly as Their Keto-Analogues during Prolonged Starvation in Obese Subjects
}

\author{
Daniel G. SAPir, Oliver E. Owen, Thomas Pozefsky, and \\ MACKENZIE WALSER \\ From the Departments of Medicine and Pharmacology and Experimental \\ Therapeutics, The Johns Hopkins University School of Medicine, Baltimore, \\ Maryland 21205 and The Department of Medicine, Temple University School \\ of Medicine, Philadelphia, Pennsylvania 19140
}

A B S T R A C T 11 normal obese subjects were fasted for 33 days. In five, who served as controls, urine urea nitrogen excretion remained constant for 2 wk thereafter. The other six were given seven daily infusions containing $6-8 \mathrm{mmol}$ each of the $\alpha$-keto-analogues of valine, leucine, isoleucine, phenylalanine, and methionine (as sodium salts) plus 3-4 mmol each of the remaining essential amino acids (lysine, threonine, tryptophan, and histidine). Rapid amination of the infused ketoacids occurred, as indicated by significant increases in plasma concentrations of valine, leucine, isoleucine, alloisoleucine, phenylalanine, and methionine. Glutamine, glycine, serine, glutamate, and taurine fell significantly. Blood glucose, ketone bodies, plasma free fatty acids, and serum immunoreactive insulin concentrations were unaltered. Urine urea nitrogen fell from 1.46 to $0.89 \mathrm{~g} /$ day on the last day of infusions; 5 days later it was still lower $(0.63 \mathrm{~g} /$ day $)$ and in two subjects studied for 9 and 17 days postinfusion it remained below preinfusion control values. Urine ammonia, creatinine, and uric acid were unaltered. Nitrogen balance became less negative during and after infusions. The results indicate that this mixture of essential amino acids and their keto-analogues facilitates nitrogen sparing during prolonged starvation, in part by conversion of the ketoacids to amino acids and in part by altering mechanisms of nitrogen conservation. The latter effect persists after the ketoacids are metabolized.

Preliminary accounts of this work have appeared in: 1974. Clin. Res. 22: 42A. (Abstr.) and 1974. J. Clin. Invest. 53 : 70a. (Abstr.).

Reccived for publication 17 April 1974 and in revised form 11 June 1974.

\section{INTRODUCTION}

During prolonged fasting in man, a progressive reduction occurs in external losses of nitrogen. The mechanism of diminished urea formation has been studied in some detail. The principal amino acids released from muscle during prolonged fasting, as well as in the postabsorptive state, are alanine and glutamine (1-3). Release of both of these amino acids falls during prolonged starvation $(2,3)$. Alanine is the principal amino acid for hepatic gluconeogenesis (4) and its nitrogen is then used for urea synthesis. Glutamine is principally taken up by the intestine (5-7) and by the kidney (8). In the intestine, this uptake results in the release of urea precursors into the portal vein (9). In the kidney the uptake of glutamine results chiefly in the formation of urinary ammonia (10). Thus in prolonged starvation, reduced splanchnic uptake of alanine and glutamine contributes to diminished urea formation $(3,4)$.

Keto-analogues of five of the essential amino acids are aminated both in liver and muscle of normal rats (11). They can serve as dietary substitutes for the corresponding amino acids in growing rats (12) and also in normal and uremic men (13-17).

The present studies were undertaken to determine whether these compounds can further promote nitrogen conservation during total starvation in obese human subjects. Since these keto-analogues reduce the concentration of glutamine in the perfused rat liver and to a lesser extent the concentration of alanine in perfused rat muscle (11), they might reduce the amounts of nitrogen derived from the catabolism of these two amino acids and requiring disposal as urea. These compounds 
may also reduce the loss of nitrogen from muscle by replenishing stores of limiting essential amino acids.

A complete mixture (five keto-analogues and four amino acids) was used on the premise that the carbon skeletons of all nine essential amino acids would be required to promote nitrogen conservation. We have assumed in these studies that histidine is essential in normal subjects, as recently reported in preliminary form by Kopple and Swenseid (18). Urea excretion did indeed decrease when this mixture was infused, and nitrogen balance became less negative. Unexpectedly, enhanced nitrogen conservation persisted for as long as 17 days after the infusions were discontinued.

\section{METHODS}

Subjects. 11 normal obese female subjects were admitted to the Johns Hopkins Clinical Research Center to undergo therapeutic weight loss by starvation. The mean ages, weights, and heights of these subjects were $33 \mathrm{yr}$, (range 21-43), $119.6 \mathrm{~kg}$ (range 93-137 kg) and $168 \mathrm{~cm}$ (range $160-175 \mathrm{~cm}$ ), respectively. 3 of the 11 subjects ( 2 in the experimental group and 1 in the control group) exhibited mild glucose intolerance. After each was fully informed of the purposes and risks of undergoing the protocol, consent was obtained. A multivitamin capsule was given daily. Distilled water was provided ad lib.

Five of the six subjects in the experimental group were starved for 33 days, when a steady state of urea nitrogen excretion was established. On the 34th day of starvation, the first of seven daily infusions of the $\alpha$-keto-analogues of valine, leucine, isoleucine, methionine, and phenylalanine (as sodium salts) and the amino acids L-histidine, L-tryptophan, L-threonine, and L-lysine monohydrochloride were administered intravenously in $250 \mathrm{ml}$ water over a 3-h period. The infusions each contained keto-val, ${ }^{1} 6.9 \mathrm{mmol}$; keto-leu, $8.48 \mathrm{mmol}$; keto-phe, $6.12 \mathrm{mmol}$; keto-ile, 5.79 mmol; keto-met, $7.42 \mathrm{mmol}$; L-histidine, $3.48 \mathrm{mmol}$; Lthreonine, $4.2 \mathrm{mmol}$; L-tryptophan, $1.22 \mathrm{mmol}$; and L-lysine monohydrochloride, $3.48 \mathrm{mmol}$. These amounts represent approximately the minimal daily requirements for these amino acids defined by Rose (see reference 17), plus histidine. They were given between 10:30 a.m. and 1:30 p.m. The total nitrogen content was $0.36 \mathrm{~g} / \mathrm{day}$. The sixth subject was starved for 22 days and then received infusions containing one and one-half times these quantities of ketoacids but identical amounts of the amino acids. In this patient, infusions were administered on the 1st and 4th through 7th days of a 7-day study period. No side effects of the infusions were noted. In four of these subjects starvation was continued for 5-17 days after cessation of the infusions.

Infusions. The sodium salts of the ketoacids were synthesized as previously described (17). Sodium phenylpyruvate was first added to sterile, pyrogen-free water by heating. The remaining compounds, which dissolve readily without heating, were then added. The solution was then sterilized by

${ }^{1}$ Abbreviations used in this paper: keto-ile, $\alpha$-keto- $\beta$ methylvaleric acid; keto-leu, $\alpha$-ketoisocaproic acid; ketomet, $\alpha$-keto- $\gamma$-methylthiobutyric acid; keto-phe, phenylpyruvic acid; keto-val, $\alpha$-keto-isovaleric acid; AcAc, acetoacetate; $\beta$-OHB, $\beta$-hydroxybutyrate; IRI, immunoreactive insulin.
Millipore filtration (Millipore Corp., Bedford, Mass.) and dispensed into vials containing $50 \mathrm{ml}$ each. All of these operations were conducted in a laminar flow hood. One vial was tested for sterility and pyrogenicity according to U. S. Pharmacopera procedures. The remaining vials were stored at $-20^{\circ} \mathrm{C}$ until use. At the time of infusion, a vial was thawed in warm water and then diluted to $250 \mathrm{ml}$ with sterile pyrogen-free water. This solution was administered within $4 \mathrm{~h}$ of thawing from a foil-covered flask through a Millipore filter.

Blood and urine collections. Blood samples were obtained only in the experimental group. "Arterialized" blood samples (19) for determination of plasma amino acids, blood glutamine, and blood ketone bodies were collected from a superficial vein in the dorsum of the hand after the subject's arm had been immersed in hot water for $15 \mathrm{~min}$. The mean $\mathrm{Po}_{2}$, measured in all samples, was $81 \pm 2 \mathrm{~mm} \mathrm{Hg}$. All other analyses were carried out on venous blood. Blood was obtained before, $1 \mathrm{~h}$ after, and $18 \mathrm{~h}$ after the first infusion, and again 7 days later, before and $1 \mathrm{~h}$ after the last infusion. Additional blood samples were obtained periodically while fasting continued for 5-17 more days.

Daily 24-h urine collections were obtained using mineral oil, thymol, and chloroform as preservatives. Sulfosalicylic acid supernates of plasma for amino acid analysis and perchloric acid supernates for glutamine analysis were prepared promptly. Urine samples and protein-free supernates of plasma were stored at $-20^{\circ} \mathrm{C}$ until analyzed.

Chenical determinations. Plasma amino acids were determined on a Beckman Amino Acid Analyzer (model 121, Beckman Instruments, Inc., Spinco Div., Palo Alto, Calif.). Whole blood acetoacetate (AcAc), $\beta$-hydroxybutyrate $(\beta$ $\mathrm{OHB})$, glucose, $\mathrm{pH}$, plasma FFA, and total $\mathrm{CO}_{2}$ content and serum immunoreactive insulin (IRI) were measured by the methods cited previously (20). Glutamine was measured according to Lund (21). Serum urea nitrogen was measured by diacetyl monoxime (11), while urine urea nitrogen was determined by a Technicon AutoAnalyzer (Technicon Instruments Corp., Tarrytown, N. Y.) (22). Urine ammonia was measured by the Kaplan method (23). Urine $\mathrm{pH}$ was determined with a Radiometer glass electrode (Radiometer Co., Copenhagen) coupled to an Orion $\mathrm{pH}$ meter (Orion Research, Inc., Cambridge, Mass.). The $\mathrm{PO}_{2}$ of arterialized blood was determined with the Clark electrode (Blood Gas Analyzer, 313, Instrumentation Laboratory, Inc., Lexington, Mass.). Nitrogen balance was calculated from measured intake (attributable only to infused amino acids) and total urinary nitrogen calculated as the sum of urea, ammonium, creatinine, and uric acid. This sum approximates total urinary nitrogen (17). Defecation occurred rarely during the study period. Skin and fecal losses of nitrogen were ignored.

Statistical analy'sis. The statistical significance of measured changes in each subject was examined by Student's $t$ test for paired samples. The presence of a steady state of urine urea nitrogen excretion in the control period preceding administration of the ketoacid-amino acid mixture, and also in the control group of five subjects, was verified in this way. Values for each subject's daily urine urea nitrogen excretion, from day 34 on, were compared with mean values for days $29-33$ of starvation.

Plasma amino acid concentrations on the morning before the first infusion were not significantly different from morning values preceding the last infusion. They have therefore been combined. Immediate postinfusion changes in plasma amino acids, FFA, blood AcAc, $\beta-\mathrm{OHB}$ and 
TABLE I

The Effect of Ketoacid Infusions on Plasma Amino Acids in Starving Obese Subjects

\begin{tabular}{|c|c|c|c|c|}
\hline & $\begin{array}{l}\text { Preinfusion } \\
\quad \text { values } \\
(n=10)\end{array}$ & $\begin{array}{c}1 \mathrm{~h} \\
\text { postinfusion } \\
(n=10)\end{array}$ & $\begin{array}{c}18 \mathrm{~h} \\
\text { postinfusion } \\
(n=5)\end{array}$ & $\begin{array}{l}5-10 \text { days } \\
\text { after last } \\
\text { infusion } \\
(n=4)\end{array}$ \\
\hline \multicolumn{5}{|c|}{ Amino acids corresponding to infused ketoacids } \\
\hline $\begin{array}{l}\text { Valine, } \mu M \\
\text { Leucine, } \mu M \\
\text { Isoleucine, } \mu M \\
\text { Alloisoleucine, } \mu M \\
\text { Methionine, } \mu M \\
\text { Phenylalanine, } \mu M\end{array}$ & $\begin{array}{c}168.7 \pm 11.2 \\
105.0 \pm 8.9 \\
69.4 \pm 4.8 \\
0 \\
19.0 \pm 0.7 \\
48.0 \pm 1.6\end{array}$ & $\begin{array}{c}223.4 \pm 16.0^{*} \\
145.5 \pm 23.4 \ddagger \\
99.0 \pm 9.4^{*} \\
27.9 \pm 4.9^{*} \\
48.9 \pm 7.9 \ddagger \\
74.5 \pm 5.0 \ddagger\end{array}$ & $\begin{array}{c}178.0 \pm 33.7 \\
111.8 \pm 19.9 \\
74.4 \pm 11.4 \\
10.3 \pm 2.6 \ddagger \\
22.8 \pm 2.9 \\
54.4 \pm 2.1\end{array}$ & $\begin{array}{r}139.7 \pm 17.6 \\
84.4 \pm 14.2 \\
63.2 \pm 10.1 \\
0 \\
21.2 \pm 2.3 \\
47.1 \pm 2.8\end{array}$ \\
\hline \multicolumn{5}{|c|}{ Amino acids infused as such } \\
\hline $\begin{array}{l}\text { Threonine, } \mu M \\
\text { Lysine, } \mu M \\
\text { Histidine, } \mu M\end{array}$ & $\begin{array}{c}214.5 \pm 15.6 \\
142.0 \pm 10.9 \\
54.6 \pm 1.3\end{array}$ & $\begin{array}{c}250.7 \pm 22.08 \\
151.4 \pm 19.0 \\
62.9 \pm 3.7\end{array}$ & $\begin{array}{c}231.5 \pm 20.3 \\
123.0 \pm 12.9 \\
56.2 \pm 3.2\end{array}$ & $\begin{array}{c}221.7 \pm 5.3 \\
149.0 \pm 19.0 \\
56.0 \pm 2.9\end{array}$ \\
\hline \multicolumn{5}{|l|}{ Other amino acids } \\
\hline $\begin{array}{l}\text { Taurine, } \mu M \\
\text { Serine, } \mu M \\
\text { Proline, } \mu M \\
\text { Glutamate, } \mu M \\
\text { Glutamine, } \| \mu M \\
\text { Citrulline, } \mu M \\
\text { Glycine, } \mu M \\
\text { Alanine, } \mu M \\
\alpha \text {-Aminobutyrate, } \mu M \\
\text { Cystine, } \mu M \\
\text { Tyrosine, } \mu M \\
\text { Ornithine, } \mu M \\
\text { Arginine, } \mu M\end{array}$ & $\begin{array}{c}77.2 \pm 7.4 \\
114.4 \pm 5.2 \\
169.3 \pm 19.8 \\
91.5 \pm 9.0 \\
363.0 \pm 18.0 \\
19.1 \pm 1.6 \\
300.1 \pm 27.3 \\
141.7 \pm 8.9 \\
37.6 \pm 1.9 \\
103.1 \pm 5.7 \\
53.6 \pm 2.0 \\
34.3 \pm 3.7 \\
50.4 \pm 3.7\end{array}$ & $\begin{array}{c}65.5 \pm 7.9 \S \\
99.0 \pm 9.9 \S \\
140.5 \pm 20.4 \\
83.7 \pm 9.0 \S \\
310.6 \pm 20.1 \ddagger \\
21.2 \pm 2.6 \\
247.5 \pm 28.5 \ddagger \\
126.9 \pm 10.4 \\
40.1 \pm 2.8 \\
111.7 \pm 6.1 \\
52.8 \pm 3.0 \\
38.1 \pm 9.1 \\
47.7 \pm 4.5\end{array}$ & $\begin{array}{c}80.8 \pm 8.7 \\
114.5 \pm 11.2 \\
155.8 \pm 28.3 \\
108.8 \pm 16.1 \\
366.6 \pm 32.7 \\
19.3 \pm 3.9 \\
318.5 \pm 31.5 \\
164.5 \pm 14.4 \\
38.4 \pm 7.7 \\
112.9 \pm 10.2 \\
61.5 \pm 3.9 \\
37.7 \pm 13.5 \\
44.5 \pm 5.6\end{array}$ & $\begin{aligned} 71.1 & \pm 4.5 \\
125.1 & \pm 9.9 \\
171.3 & \pm 21.5 \\
72.5 & \pm 9.2 \\
446.7 & \pm 46.4 \\
18.1 & \pm 2.1 \\
329.1 & \pm 50.1 \\
147.0 & \pm 24.3 \\
26.4 & \pm 5.1 \\
84.8 & \pm 14.6 \\
51.7 & \pm 5.8 \\
31.0 & \pm 0.5 \\
61.2 & \pm 6.5\end{aligned}$ \\
\hline
\end{tabular}

${ }^{*} P<0.001$.

$\ddagger P<0.01$.

$\S P<0.05$.

\| Whole blood.

glucose, and serum IRI were determined by comparing pre- and postinfusion values obtained in each subject during the first and seventh infusions. The changes which occurred in these parameters were not significantly different between the 1 st and 7 th days (by paired $t$ test); hence the results have been combined. All results are expressed as means \pm SEM.

\section{RESULTS}

Plasma amino acids. After 33 days of starvation, plasma valine, alanine, citrulline, ornithine, lysine, and arginine concentrations were reduced, and glycine was increased, as compared with overnight fasting values (2). These changes are similar to those already reported $(4,24)$. Whole blood glutamine was also low, in accordance with the observations of Aoki, Muller, and Cahill (25).

$1 \mathrm{~h}$ after infusion of the ketoacid-amino acid mixture, plasma amino acids corresponding to the infused keto- acids had all increased significantly (Table I, Fig. 1). Alloisoleucine, which was too low to measure in preinfusion samples, rose to $27.9 \pm 4.9 \mu \mathrm{M}$. When alloisoleucine and isoleucine are combined, the increments in each amino acid varied in the sequence isoleucine + alloisoleucine $>$ valine $>$ leucine $>$ methionine $>$ phenylalanine, and totaled $210 \pm 30 \mu \mathrm{M} \quad(n=5)$. The average increments in plasma concentrations of those amino acids present in the infusion (threonine, lysine, and histidine; tryptophan was not measured) was $18 \pm 9 \mu \mathrm{M} \quad(n=3)$. Only the increase in threonine was significant $(P<$ 0.05 . This may reflect the somewhat smaller quantities of amino acids infused, or a different temporal course of plasma concentrations for the two groups of compounds. The concentrations of several amino acids decreased significantly. When measured $1 \mathrm{~h}$ post-infusion, plasma glycine and blood glutamine decreased substantially, while small but significant decreases occurred in taurine, 
serine, and glutamate. The total of these decrements was $140 \mu \mathrm{M}$.

By the morning after infusion, all amino acid concentrations (with the exception of alloisoleucine) had returned to preinfusion values (Table I). Since no significant change other than in alloisoleucine was detectable between the first and last infusion day in morning values for plasma amino acid concentrations, these repeated infusions induced no progressive alterations in amino acid concentrations. Measurements made 5-10 days after the infusion period, in the four subjects who continued to fast, revealed no significant changes except that alloisoleucine again became unmeasurably low.

Total plasma ketoacids were measured $1 \mathrm{~h}$ postinfusion in two subjects. The increase was $0.31 \mathrm{mM}$. As noted previously (11), this method measures $\alpha$-ketoglutarate and pyruvate, as well as the ketoacids infused, but does not measure AcAc or $\alpha$-ketoglutaramate. Since the total ketoacids infused amounted to $35 \mathrm{mmol}$, and the concentration of these compounds in normal muscle and liver is about half of that in plasma (11), intravenous equilibration throughout their volume of distribution in a subject of $60 \mathrm{~kg}$ lean body mass would have resulted in a plasma concentration of approximately $1 \mathrm{mM}$. Thus the observed increment in plasma concentration again suggests the rapid rate of metabolism of these compounds (11).

Nitrogen balance and excretion. Urinary urea nitrogen excretion (Fig. 2) in the infused subjects fell progressively during the infusion period. The control value of $1.46 \pm 0.22 \mathrm{~g} /$ day observed on the $33 \mathrm{rd}$ day of starvation fell to $0.88 \pm 0.14 \mathrm{~g} /$ day $(P<0.01)$ on the last day of the infusion period. On the 5 th day after cessation of the infusions, the daily urine urea nitrogen excretion of $0.75 \pm 0.09 \mathrm{~g} /$ day was still significantly lower $(P<$ $0.025)$ than the control value. In the two subjects studied for 9 and 17 days, respectively, after infusions, urea nitrogen excretion was 0.62 and $0.78 \mathrm{~g} /$ day on the last day. In the one subject infused after 22 days of fasting, control urea nitrogen excretion was $2.64 \pm 0.16 \mathrm{~g} /$ day during the last 5 days before administration of ketoacidamino acid infusions. When the values from this subject are included with the other five subjects undergoing infusions, the mean daily urea nitrogen excretion on the last day of the control period was $1.58 \pm 0.21 \mathrm{~g} / \mathrm{day}$, significantly higher $(P<0.025)$ than on the last day of infusion $(0.82 \pm 0.13 \mathrm{~g} /$ day $)$.

The upper panel of Fig. 2 depicts the daily urea nitrogen excretion in the control group. There was no significant change between days 29 and 46 of starvation.

Serum urea nitrogen concentration of the five experimental subjects just before the first ketoacid-amino acid infusion was $6.0 \pm 0.5 \mathrm{mg} / 100 \mathrm{ml}$. It fell significantly $(P<0.005)$ to $3.6 \pm 0.5 \mathrm{mg} / 100 \mathrm{ml}$ on the last day of the
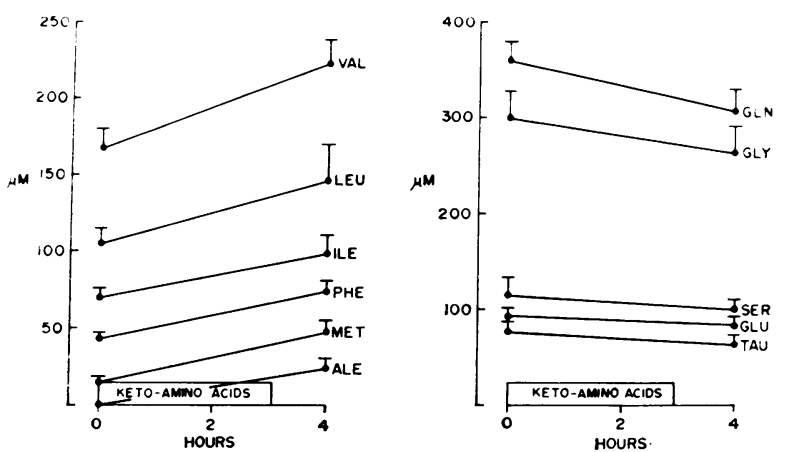

FIGURE 1 Changes in circulating amino acids during infusion of ketoacid-amino acid mixture in starving obese subjects. The left-hand panel shows the increases in plasma amino acids corresponding to the infused ketoacids. The right hand panel shows those amino acids which fell significantly during the infusion.

infusion period and remained below the control value at $3.9 \pm 0.6 \mathrm{mg} / 100$ in the four subjects who continued to fast. Urea clearance on the last day of the control period (33rd day of starvation) was $17.5 \pm 3.1 \mathrm{ml} / \mathrm{min}$. It remained unchanged at $17.9 \pm 2.9 \mathrm{ml} / \mathrm{min}$ and $14.4 \pm 2.6$ $\mathrm{ml} / \mathrm{min}$ on the last day of the infusion week and on the 5 th day thereafter, respectively. Creatinine clearance and the ratio of urea clearance to creatinine clearance also remained unchanged throughout the study.

The following urinary measurements were unchanged when comparison was made of the last day before infusions, the last day of the infusions, and the 5th day thereafter; creatinine $(1.12 \pm 0.11,1.13 \pm 0.08$, and $1.07 \pm$ $0.18 \mathrm{~g} /$ day $)$, ammonium $(167 \pm 2,153 \pm 21$, and $157 \pm 13$ meq/day) and uric acid (200 $\pm 42,217 \pm 37$, and $167 \pm 39$ $\mathrm{mg} /$ day. Urine volume was also constant.

Nitrogen balance improved significantly $(P<0.01)$ from $-4.17 \pm 0.38 \mathrm{~g} /$ day on the $33 \mathrm{rd}$ day to $-3.33 \pm$

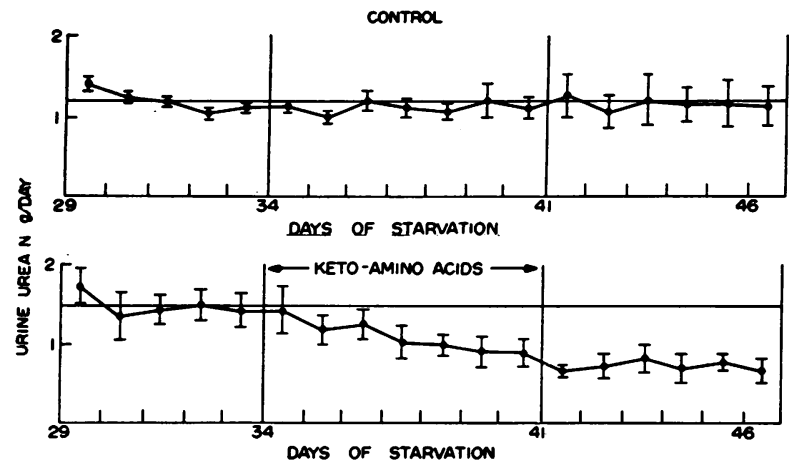

FIGURE 2 Urine urea nitrogen during daily ketoacid-amino acid infusions in starving obese subjects. In control subjects (above), urea excretion remains constant during this period. During the infusions, urea excretion decreases and remains low in the ensuing period. 
TABLE II

Effect of Ketoacid Infusions on Blood and Urine Ketone Bodies, Plasma FFA, Blood Glucose, and Serum IRI Concentrations

\begin{tabular}{|c|c|c|c|c|}
\hline & $\begin{array}{l}\text { Preinfusion } \\
\text { values } \\
(n=10)\end{array}$ & $\begin{array}{c}1 \mathrm{~h} \\
\text { postinfusion } \\
(n=10)\end{array}$ & $\begin{array}{c}18 \mathrm{~h} \\
\text { postinfusion } \\
(n=5)\end{array}$ & $\begin{array}{l}5-10 \text { days } \\
\text { after last } \\
\text { infusion } \\
(n=4)\end{array}$ \\
\hline \multicolumn{5}{|c|}{ Circulating substrates and insulin } \\
\hline $\begin{array}{l}\text { AcAc, } m M \\
\beta \text {-OHB, } m M \\
\text { FFA, } m M \\
\text { Glucose, } m g / d l \\
\text { IRI, } \mu U / m l\end{array}$ & $\begin{array}{c}1.38 \pm 0.06 \\
5.43 \pm 0.41 \\
1.68 \pm 0.33 \\
71 \pm 3 \\
16 \pm 2\end{array}$ & $\begin{array}{c}2.04 \pm 0.21 \\
68 \pm 3 \\
20 \pm 3\end{array}$ & $\begin{array}{c}1.50 \pm 0.06 \\
5.99 \pm 0.36 \\
1.80 \pm 0.11 \\
70 \pm 3 \\
18 \pm 3\end{array}$ & $\begin{array}{c}1.66 \pm 0.19 \\
6.51 \pm 1.04 \\
1.28 \pm 0.18 \\
66 \pm 2 \\
14 \pm 4\end{array}$ \\
\hline IRI, $\mu U / m l$ & $\begin{array}{l}\text { Preinfusion } \\
\text { day (5) }\end{array}$ & \multicolumn{2}{|c|}{$\begin{array}{c}\text { Last day } \\
\text { of infusions (5) }\end{array}$} & $\begin{array}{c}5 \text { days } \\
\text { later }(4)\end{array}$ \\
\hline \multicolumn{5}{|l|}{ Urinary ketone bodies } \\
\hline $\begin{array}{l}\text { AcAc, } m m o l / d a y \\
\beta-\mathrm{OHB}, m m o l / d a y\end{array}$ & $\begin{array}{l}14 \pm 2 \\
87 \pm 7\end{array}$ & \multicolumn{2}{|c|}{$\begin{array}{c}19 \pm 3^{*} \\
123 \pm 11^{*}\end{array}$} & $\begin{array}{l}13 \pm 2 \\
81 \pm 6\end{array}$ \\
\hline
\end{tabular}

* Significantly different from preinfusion day and 5 days postinfusion $(P<0.01)$.

$0.36 \mathrm{~g} /$ day on the last day of ketoacid infusions. Nitrogen balance on the 5 th day after stopping infusions, $-3.27 \pm$ $0.29 \mathrm{~g} /$ day was still less negative $(P<0.05)$ than the control nitrogen balance. Significant increases (Table II) in the excretion of both AcAc and $\beta$-OHB were observed when the last day of the infusion period was compared with the last day of the control period or the 5 th day of the postinfusion period. There were no significant changes in blood glucose, blood ketone bodies, plasma FFA, or serum IRI concentrations (Table II). In the one subject examined, the increased rate of ketone body excretion was accompanied by a rise in sodium excretion from 3.0 to $58.9 \mathrm{meq}$ on the last days of the control and infusion period, respectively, reflecting the administration of the sodium salts of the ketoacids.

Arterialized blood $\mathrm{pH}, 7.45 \pm 0.01$, was significantly $(P<0.01)$ higher at the end of the infusion period, when compared with the control value, $7.41 \pm 0.01$. Plasma bicarbonate rose from $18.1 \pm 0.8$ to $20.2 \pm 0.8 \mathrm{mM}$ over this interval. Urine $\mathrm{pH}$ was constant before, during, and after infusions (6.09 $\pm 0.09,5.99 \pm 0.10$, and 6.04 \pm 0.06 , respectively).

\section{DISCUSSION}

These results show that daily infusions of keto-analogues of five essential amino acids, along with the four remaining essential amino acids, reduce urea excretion and spare nitrogen during prolonged fasting. This effect persists long after the ketoacids are metabolized.

There can be little doubt that conversion of the ketoanalogues to the corresponding amino acids occurs under these conditions. The rapid increase in plasma concen- trations of these specific amino acids, and no others (except those present in the infusion) is strong presumptive evidence. The only conceivable alternative is an effect of ketoacids on amino acid distribution. In previous studies on normal rats (11), no evidence could be found for an effect of these compounds on the distribution of amino acids between cells and plasma.

Although this conclusion seems certain from the qualitative viewpoint, quantitative estimates of amination vs. degradation rates of these ketoacids cannot be inferred from these observations. The reduction in urinary urea nitrogen excretion during the infusions eventually approximated the amount of nitrogen that would have been required to aminate the infused ketoacids $(0.49$ $\mathrm{g} /$ day). But the persistence of this reduction in urea excretion during the ensuing week shows that attempts to estimate the efficiency of ketoacid utilization on this basis are futile.

It is also of interest that this progressive reduction in urea excretion ocurs without a progressive change in individual plasma amino acids. The morning after infusion, concentrations of all measured amino acids had returned to preinfusion levels. Furthermore, there was no difference between the preinfusion values on the 1st and 7 th days, or between these values and those observed 5-10 days after the last infusion. The improvement in nitrogen balance could be attributable to enzymatic or hormonal alterations or to altered metabolism of carbohydrate or fat. However, the measured parameters of carbohydrate and fat metabolism were unaltered except for a modest increase in ketonuria. Since this latter effect was not observed in the week after infusions, while 
improved nitrogen conservation persisted, it is unlikely to be of any significance in explaining the results. IRI concentrations in serum also remained constant, at the low value characteristically observed in prolonged starvation (10).

Glucagon was not measured. Glucagon levels are occasionally elevated in prolonged fasting (26). Furthermore, glucagon promotes gluconeogenesis (27), and stimulates activity of urea cycle enzymes in the liver (28). Thus a reduction in glucagon levels might lower urea formation in fasting. Amino acids most effective in stimulating glucagon release include asparagine, glycine, and phenylalanine (29). However, no evidence has been presented that glucagon, at physiological levels, alters urea formation in man.

In the postinfusion week, urea formation was reduced despite unaltered plasma amino acids. This must mean that amino acid release from muscle was diminished. The major amino acids released from muscle in fasting are alanine and glutamine (1-3). Conceivably, cellular stores of essential amino acids may have been repleted during infusions, even though preinfusion plasma concentrations were constant. Increased availability of these essential amino acids may promote anabolism in muscle.

The specific amino acids that decreased immediately postinfusion were glutamine, taurine, glycine, serine, and glutamate. The fall in glutamine is to be expected in view of previous observations of the effects of these compounds in the isolated perfused rat liver (11). Glutamine was identified as the major nitrogen donor for aminating these ketoacids in liver, either indirectly or directly (via glutamine transaminase). No explanation for the particular involvement of glycine, serine, or taurine is apparent. Glutamate probably decreased owing to transamination or deamination.

Other minor differences existed between the control and experimental groups: for example, a small increase was observed in plasma $\mathrm{pH}$ and bicarbonate in the infused subjects; sodium intake was greater by $35 \mathrm{meq}$; and the infused ketoacids, if oxidized, could have yielded a small source of energy (less than $30 \mathrm{cal}$ ). Evidence is lacking that small changes in $\mathrm{pH}$ or sodium balance modify nitrogen excretion during starvation. We have previously reported (20) that daily administration of $30 \mathrm{cal}$ to starving subjects does not alter excretion.

These experiments show that when physiologic mechanisms for conserving nitrogen during starvation reach a maximum, nitrogen losses can be further reduced by infusion of ketoacids. No toxicity or metabolic derangements were observed and no accumulation of ketoacids in plasma occurred. Further experiments will be necessary to establish the optimal mixture and dosage of these compounds for minimizing nitrogen wastage, as well as their efficacy early in starvation, when nitrogen losses are far greater.

\section{ACKNOWLEDGMENTS}

Technical assistance was provided by Sylvia Butler, Nancy Chambers, Shrikant Dighe, Valerie Hammond, Maria Mozzoli, Lyle Myerberg, and Karen Popkave.

This research was supported by U. S. Public Health Service/NIH grants AM 15603, RR 35, HE 3303, RR 349, and AM 14754.

\section{REFERENCES}

1. Pozefsky, T., P. Felig, J. D. Tobin, J. S. Soeldner, and G. F. Cahill, Jr. 1969. Amino acid balance across the tissues of the forearm in postabsorptive man. The effects of insulin at two dose levels. J. Clin. Invest. 48: 22732282.

2. Felig, P., E. Marliss, T. Pozefsky, and G. F. Cahill, Jr. 1970. Alanine: key role in gluconeogenesis. Science (Wash. D. C.). 167 : 1003-1004.

3. Marliss, E. B., T. T. Aoki, T. Pozefsky, and G. F. Cahill, Jr. 1971. Muscle and splanchnic glutamine and glutamate metabolism in postabsorptive and starving man. J. Clin. Invest. 50: 814-817.

4. Felig, P., O. E. Owen, J. Wahren, and G. F. Cahill, Jr. 1969. Amino acid metabolism during prolonged starvation. J. Clin. Invest. 48: 584-594.

5. Addae, S. K., and W. D. Lotspeich. 1969. Relation between glutamine utilization and production in metabolic acidosis. Am. J. Physiol. 215: 269-277.

6. Elwyn, P. H., H. C. Parikh, and W. C. Shoemaker. 1968. Amino acid movements between gut, liver, and periphery in unanesthetized dogs. Am. J. Physiol. 215: 1260-1275.

7. Felig, P., J. Wahren, I. Karl, E. Cerasi, R. Luft, and D. M. Kipnis. 1973. Glutamine and glutamate metabolism in normal and diabetic subjects. Diabetes. 22 : 573 576.

8. Van Slyke, D. D., R. A. Phillips, P. B. Hamilton, R. M. Archibald, P. H. Futcher, and A. Hiller. 1943. Glutamine as source material for urinary ammonia. J. Biol. Chem. 150: 481-482.

9. Windmueller, H. G., and A. E. Spaeth. 1973. Plasma glutamine: large net uptake and metabolism by intestine. Fed. Proc. $32:$ 321. (Abstr.)

10. Owen, O. E., P. Felig, A. P. Morgan, J. Wahren, and G. F. Cahill, Jr. 1969. Liver and kidney metabolism during prolonged starvation. J. Clin. Invest. 48: 574 583.

11. Walser, M., P. Lund, N. B. Ruderman, and A. W. Coulter. 1973. Synthesis of essential amino acids from their $\alpha$-keto analogues by perfused rat liver and muscle. J. Clin. Invest. 52 : 2865-2877.

12. Close, J. H. 1974. The use of amino acid precursors in nitrogen-accumulation diseases. N. Engl. J. Med. 290: 663-667.

13. Richards, P., B. J. Houghton, C. L. Brown, and E. Thompson. 1971. Synthesis of phenylalanine and valine by healthy and uremic men. Lancet. 2 : 128-134.

14. Gallina, D. L., J. M. Dominguez, J. C. Hoschian, and J. R. Barrio. 1971. Maintenance of nitrogen balance in a young woman by substitution of $\alpha$-ketoisovaleric acid for valine. J. Nutr. $101: 1165-1168$.

15. Giordano, C., C. De Pascale, M. E. Phillips, N. G. De Santo, P. Fürst, C. L. Brown, B. J. Houghton, and P. Richards. 1972. Utilisation of ketoacid analogues of valine and phenylalanine in health and uremia. Lancet. 1: 178-182. 
16. Rudman, D. 1971. Capacity of human subjects to utilize keto analogues of valine and phenylalanine. J. Clin. Invest. 50: 90-96.

17. Walser, M., A. W. Coulter, S. Dighe, and F. R Crantz. 1973. The effect of keto-analogues of essential amino acids in severe chronic uremia. J. Clin. Invest. 52: 678-690.

18. Kopple, J. D., and M. Swenseid. 1974. Histidine: an essential amino acid in adult humans. Clin. Res. 22: 193A. (Abstr.)

19. Forster, H. V., J. A. Dempsey, J. Thomson, E. Vidruk, and G. A. DoPico. 1972. Estimation of arterial $\mathbf{P O}_{2}$ $\mathrm{PCO}_{2}, \mathrm{pH}$, and lactate from arterialized venous blood. J. Appl. Physiol. 32 : 134-137.

20. Sapir, D. G., O. E. Owen, J. T. Cheng, R. Ginsberg, G. Boden, and W. G. Walker. 1972. The effect of carbohydrates on ammonium and ketoacid excretion during starvation. J. Clin. Invest. 51: 2093-2102.

21. Lund, P. 1970. Bestimmung mit Glutamine und Glutamine Dehydrogenase. In Methoden der Enzymatischen Analyse. H. U. Bergmeyer, editor. Verlag-Chemie, Weinheim. 2nd edition. 1671-1673.

22. Marsh, W. H., B. Fingerhut, and H. Miller. 1965. Automated and manual direct methods for the determination of blood urea. Clin. Chem. 11: 624-627.
23. Kaplan, A. 1965. Urea nitrogen and urinary ammonia. Stand. Methods Clin. Chem. 5: 245-256.

24. Adibi, S. A. 1968. Influence of dietary deprivations on plasma concentrations of free amino acids in man. $J$. Appl. Physiol. 25 : 52-57.

25. Aoki, T. T., W. A. Müller, and G. F. Cahill, Jr. 1972. Hormonal regulation of glutamine metabolism in fasting man. Adv. Enzyme Regul. 10: 145-151.

26. Marliss, E. B., T. T. Aoki, R. H. Unger, J. S. Soeldner, and G. F. Cahill, Jr. 1970. Glucagon levels and metabolic effects in fasting man. J. Clin. Invest. 49: 22562270.

27. Mallette, L. E., J. H. Exton, and C. R. Park. 1969. Effects of glucagon on amino acid transport and utilization in the perfused rat liver. J. Biol. Chem. $244: 5724$ 5728.

28. McLean, P., and F. Novello. 1965. Influence of pancreatic hormones on enzymes concerned with urea synthesis in rat liver. Biochem. J. 94: 410-422.

29. Rocha, D. M., G. R. Faloona, and R. H. Unger. 1972. Glucagon-stimulating activity of 20 amino acids in dogs. J. Clin. Invest. 51 : 2346-2351. 